Molecules 2004, 9, 968-977

molecules

ISSN 1420-3049

http://www.mdpi.org

\title{
Preparation of Poly(oxybutyleneoxymaleoyl) Catalyzed by a Proton Exchanged Montmorillonite Clay
}

Mohammed Issam Ferrahi * and Mohammed Belbachir

Laboratoire de Chimie des Polymères, Département de Chimie, Faculté des Sciences, Université d'Oran Es-Sènia BP Nº 1524 El M’Naouar, 31000 Oran, Algeria; Fax: (+213) 41416021

* To whom correspondence should be addressed; e-mail: mohammed.ferrahi@caramail.com

Received: 12 July 2004 / Accepted: 6 September 2004 / Published: 30 November 2004

\begin{abstract}
The polycondensation of tetrahydrofuran with maleic anhydride catalyzed by Maghnite- $\mathrm{H}^{+}$(Mag-H) was investigated. Maghnite is a montmorillonite sheet silicate clay that is exchanged with protons to produce Maghnite- $\mathrm{H}^{+}[1]$. It was found that the polymerization in bulk is initiated by Mag-H in the presence of acetic anhydride at $40^{\circ} \mathrm{C}$. The effects of the amounts of Mag-H and acetic anhydride were studied. The polymerization yield increased as the proportions of catalyst and acetic anhydride were increased.
\end{abstract}

Keywords: Maghnite, maleic anhydride, montmorillonite, tetrahydrofuran.

\section{Introduction}

The use of acid treated clays as a solid source of protons in a number of industrially significant reactions continues to be of interest because they constitute a widely available and inexpensive solid source of protons. They were widely employed as cracking catalysts until the 1960s [2] and are still used currently in industrial processes such as the alkylation of phenols [3] and the dimerization and polymerization of unsaturated hydrocarbons [4]. Montmorillonites have both Brönsted and Lewis acid sites and when exchanged with cations having a high charge density, such as protons, they produce highly-active catalysts for acid-catalysed reactions [5]. Intercalated organic molecules are mobile and can be highly polarized when located in the space between the charged clay layers. Organic chemists, with synthesis in mind, have so far confined their interests mainly to swellable montmorillonite clays [6-8] and almost all of the clay catalysts used have been either (a) acid-treated clays such as K-10, or (b), ion-exchanged clays such as $\mathrm{Al}^{3+}, \mathrm{Cr}^{3+}$ or $\mathrm{H}^{+}$exchanged Wyoming or Texas bentonites [9]. These 
acid-treated and cation exchanged clays can be regarded simply as solid acids that act as heterogeneous catalysts, with all of the advantages resulting from the easy removal of the catalyst from the product(s). Acid-treated clays, because of their increased surface area and swelling properties, have also been widely used as solid supports for inorganic reagents such as potassium permanganate [10], thallium(III) nitrate [11] and both copper(II) and iron(III) nitrates [12]. The ion-exchanged clays have mostly Brönsted acidity in the interlamellar zone and thus are characterised by promoting acidcatalysed reactions, often of a bimolecular type, between protonated and neighbouring unprotonated reactants [13]. These exchanged montmorillonites have been successfully used as catalysts in polymerization reactions [14].

The present study demonstrates the synthesis of poly(oxybutyleneoxymaleoyl) whose the structure differs from that of poly(oxyethyleneoxymaleoyl) in the number of carbons, as the former has two carbons more than the latter. Poly(oxyethyleneoxymaleoyl) is usually prepared from ethylene glycol and maleic anhydride. One of the biggest problems with the poly(oxybutyleneoxymaleoyl) reaction has been the butanediol, and as a result, it is preferable to use tetrahydrofuran as a source of an oxybutylene part in the polymer.

The purpose of this paper is also to study this polycondensation and examine the catalytic activity of an Algerian proton exchanged montmorillonite clay called "Maghnite- $\mathrm{H}^{+}$" (Mag-H) [15-26], a new non-toxic catalyst [24]. Mag-H can be easily separated from the polymer products and regenerated by heating to a temperature above $100{ }^{\circ} \mathrm{C}$ [24]. The effects of the relative amounts of the Mag-H and the proportion of acetic anhydride on the outcome of the polymerization are also discussed.

\section{Results and Discussion}

\section{Catalyst Structure}

The elementary analysis of the selected samples obtained using XRF and the yields obtained from the reaction of $1 \mathrm{~g}$ of each sample with $10.75 \mathrm{~mol} / \mathrm{L}$ of THF, $8.43 \mathrm{~mol} / \mathrm{L}$ of maleic anhydride and 1.28 $\mathrm{mol} / \mathrm{L}$ of acetic anhydride for 6 hours in a bulk polymerization at $40^{\circ} \mathrm{C}$ are as shown in Table 1 .

Table1 Elementary compositions of proton exchanged samples of "Maghnite- $\mathrm{H}^{+}$"

\begin{tabular}{|l|l|l|l|l|l|l|l|l|l|l|l|l|}
\hline \multirow{2}{*}{ Sample } & \multicolumn{10}{|c|}{ Composition $\mathbf{w t} \%$} & \multirow{2}{*}{ Yield\% } \\
\cline { 2 - 12 }$n$ & $\mathbf{S i O}_{\mathbf{2}}$ & $\mathbf{A l}_{\mathbf{2}} \mathbf{O}_{\mathbf{3}}$ & $\mathbf{F e}_{\mathbf{2}} \mathbf{O}_{\mathbf{3}}$ & $\mathbf{C a O}$ & $\mathbf{M g O}$ & $\mathbf{N a}_{\mathbf{2}} \mathbf{O}$ & $\mathbf{K}_{\mathbf{2}} \mathbf{O}$ & $\mathbf{T i O}_{\mathbf{2}}$ & $\mathbf{S O}_{\mathbf{3}}$ & $\mathbf{A s}$ & $\mathbf{P F}^{*}$ & \\
Raw-Maghnite & 69.39 & 14.67 & 1.16 & 0.30 & 1.07 & 0.50 & 0.79 & 0.16 & 0.91 & 0.05 & 11 & 0.0 \\
Mag-H 0.05M & 70.75 & 14.67 & 1.05 & 0.30 & 1.01 & 0.49 & 0.78 & 0.16 & 0.75 & 0.04 & 10 & 5.32 \\
Mag-H 0.10M & 71.00 & 14.60 & 1.00 & 0.30 & 0.98 & 0.39 & 0.78 & 0.16 & 0.55 & 0.04 & 10.2 & 11.62 \\
Mag-H 0.15M & 71.58 & 14.45 & 0.95 & 0.29 & 0.91 & 0.35 & 0.77 & 0.15 & 0.42 & 0.03 & 10.1 & 18.35 \\
Mag-H 0.20M & 71.65 & 14.20 & 0.80 & 0.28 & 0.85 & 0.30 & 0.77 & 0.15 & 0.39 & 0.01 & 10.6 & 22.54 \\
Mag-H 0.25M & 71.70 & 14.03 & 0.71 & 0.28 & 0.80 & 0.21 & 0.77 & 0.15 & 0.34 & 0.01 & 11 & 38.86 \\
Mag-H 0.30M & 73.20 & 13.85 & 0.70 & 0.27 & 0.78 & 0.20 & 0.76 & 0.13 & 0.31 & 0.02 & 9.78 & 30.62 \\
Mag-H 0.35M & 75.31 & 13.52 & 0.71 & 0.26 & 0.78 & 0.18 & 0.75 & 0.13 & 0.32 & 0.01 & 8.03 & 27.76 \\
\hline
\end{tabular}


The best yield was obtained using "Maghnite- $\mathrm{H}^{+} 0.25 \mathrm{M}$ ", so for this reason this sample was used to study the effects of catalyst and acetic anhydride proportions on polymerization. Acid treatment of "Raw-Maghnite" causes a reduction in octahedral content $\left(\mathrm{Al}_{2} \mathrm{O}_{3}\right)$ and resulted in an increase in the proportion of silica $\left(\mathrm{SiO}_{2}\right)$ observed.

\section{Polymerization and Product Characterization}

The results of bulk polycondensation experiments of 10.75 M THF with 8.43 M maleic anhydride induced by "Maghnite- $\mathrm{H}^{+} 0.25 \mathrm{M}$ " are reported in Table 2. For all these experiments the temperature was kept constant at $40^{\circ} \mathrm{C}$ for 6 hours.

Table 2. Polycondensation of THF with maleïc anhydride induced by "Maghnite- $\mathrm{H}^{+} 0.25 \mathrm{M}$ "

\begin{tabular}{|c|c|c|c|c|c|c|}
\hline Experiment & $\begin{array}{c}{[\mathbf{A A}]} \\
(\mathbf{m o l} / \mathbf{l})\end{array}$ & $\begin{array}{c}\text { Maghnite-H } \\
\mathbf{0 . 2 5 M ( \% )}\end{array}$ & Yield \% & $\mathbf{M n}_{\mathbf{n}}$ & $\mathbf{M}_{\mathbf{w}}$ & $\mathbf{M}_{\mathbf{w}} / \mathbf{M}_{\mathbf{n}}$ \\
\hline 1 & 1.28 & 10 & 38.86 & 625 & 3628 & 5.80 \\
2 & 1.28 & 2.5 & 18.43 & 691 & 4283 & 6.19 \\
3 & 0.19 & 2.5 & 11.68 & 738 & 4921 & 6.66 \\
\hline
\end{tabular}

[AA]: Acetic anhydride

Effect of the amount of Mag-H on the polymerization

We can see from Table 2 that the yield increases as the proportion of "Maghnite- $\mathrm{H}^{+} 0.25 \mathrm{M}$ " increases (experiments 1,2). Table 3 shows the effect of the amount of Mag-H on the polymerization yield. Indeed, using various amounts of Mag-H: 2.5, 5 and $10 \%$ by weight, the polymerization was carried out in bulk at $40{ }^{\circ} \mathrm{C}$. The polymerization yield increased with the amount of Mag-H, thus clearly showing the effect of Mag-H as a catalyst. This phenomenon is probably the result of an increase in the number of "initiating active sites" responsible of inducing polymerization, a number that is prorata to the amount of catalyst used a reaction.

Table 3: Polymer yields with time for $10.75 \mathrm{~mol} / \mathrm{L}$ of THF, $8.43 \mathrm{~mol} / \mathrm{L}$ of maleic anhydride, $0.19 \mathrm{~mol} / \mathrm{L}$ of acetic anhydride

\begin{tabular}{|c|c|c|c|c|c|c|}
\hline Time(hours) & $\mathbf{1}$ & $\mathbf{2}$ & $\mathbf{3}$ & $\mathbf{4}$ & $\mathbf{5}$ & $\mathbf{6}$ \\
\hline Amount of Maghnite $\mathbf{H}^{+}$ & \multicolumn{6}{|c|}{ Yields (\%) } \\
\hline $2.5 \%$ & 1.23 & 2.54 & 4.36 & 5.26 & 11.24 & 16.91 \\
$5 \%$ & 3.25 & 4.92 & 7.97 & 11.56 & 21.35 & 28.61 \\
$10 \%$ & 4.93 & 7.22 & 11.93 & 17.76 & 28.13 & 38.86 \\
\hline
\end{tabular}


Effect of the proportion of acetic anhydride on the polymerization

The addition of acetic anhydride to the mixture creates chain ends unable to take part in polyesterification and consequently the problem of reproducibility of molecular weight does not exist, allowing the existence of a stable polymer.

The data in Table 2 shows that the yield increases as the proportion of acetic anhydride increases. (experiments 2,3). This result is due to a multiplication of the active centers. However, the molecular weight increases when the proportion of acetic anhydride is reduced. This result is due to an increase in the number of methyl groups at the extremities of the chains that block the growth of polymer chains. These observations were followed up in a series of detailed experiments in which the variation of yield with time was been observed at two levels of acetic anhydride. Table 4 shows that increasing the acetic anhydride amounts gave higher yields.

Table 4: Polymer yields with time for $10.75 \mathrm{~mol} / \mathrm{L}$ of THF, $8.43 \mathrm{~mol} / \mathrm{L}$ of maleic anhydride, $2.5 \%$ of Maghnite- $\mathrm{H}+0.25 \mathrm{M}$.

\begin{tabular}{|c|c|c|c|c|c|c|}
\hline Time(hours) & $\mathbf{1}$ & $\mathbf{2}$ & $\mathbf{3}$ & $\mathbf{4}$ & $\mathbf{5}$ & $\mathbf{6}$ \\
\hline Acetic anhydride & \multicolumn{7}{|c|}{ Yields (\%) } \\
\hline $0.19 \mathrm{~mol} / \mathrm{L}$ & 1.23 & 2.54 & 4.36 & 5.26 & 11.24 & 16.91 \\
$1.28 \mathrm{~mol} / \mathrm{L}$ & 3.76 & 4.86 & 6.38 & 9.85 & 15.34 & 21.41 \\
\hline
\end{tabular}

\section{Characterization of products}

An investigation was devoted to the analysis of the polymer from experiment 2 in Table 2 by 300 $\mathrm{MHz}{ }^{1} \mathrm{H}-\mathrm{NMR}$ spectroscopy (Table 5). The reaction taking place is shown in the following scheme:
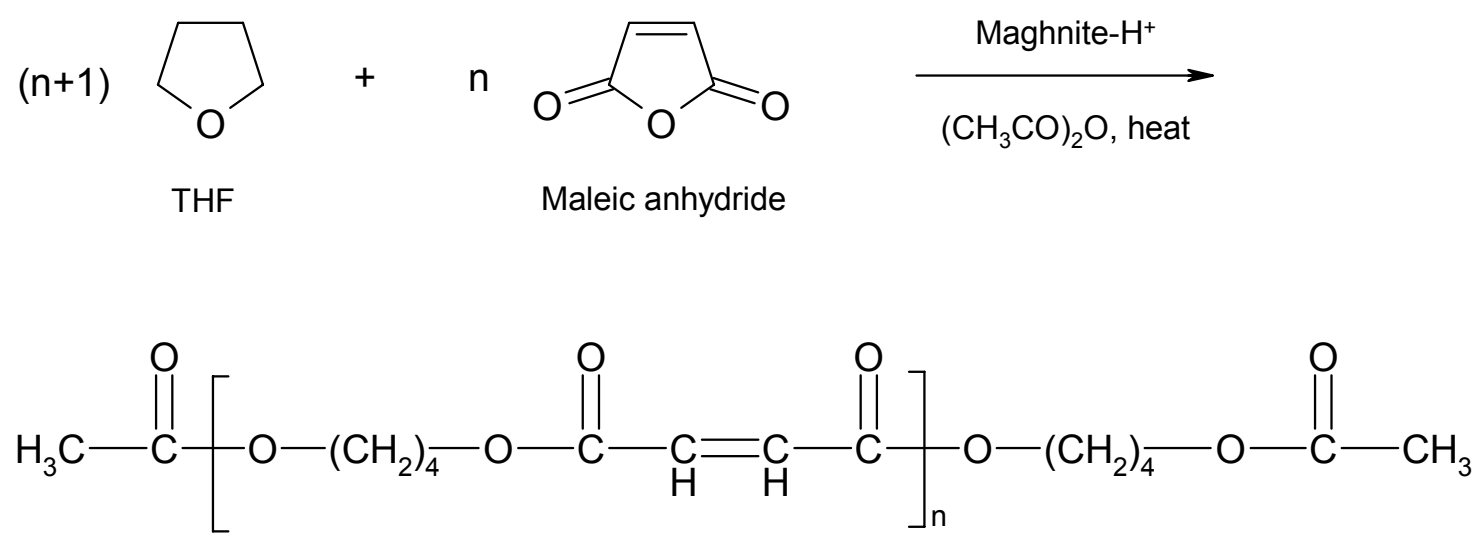

Poly(oxybutyleneoxymaleoyl) 
Table 5. Product analysis by ${ }^{1} \mathrm{H}-\mathrm{NMR}$ spectroscopy

\begin{tabular}{|c|c|c|c|c|}
\hline Proton type & (a) & (b) & (c) & (d) \\
\hline $\boldsymbol{\delta}$ in ppm & 1.67 & 1.99 & 3.57 & 7.62 \\
\hline
\end{tabular}<smiles>CCC(CC)OCCCCOC(=O)C=CCOC(C)=O</smiles>

Figure 1. ${ }^{1} \mathrm{H}-\mathrm{NMR}$ spectra of the poly(oxybutyleneoxymaleoyl) product of experiment 2 in Table 3

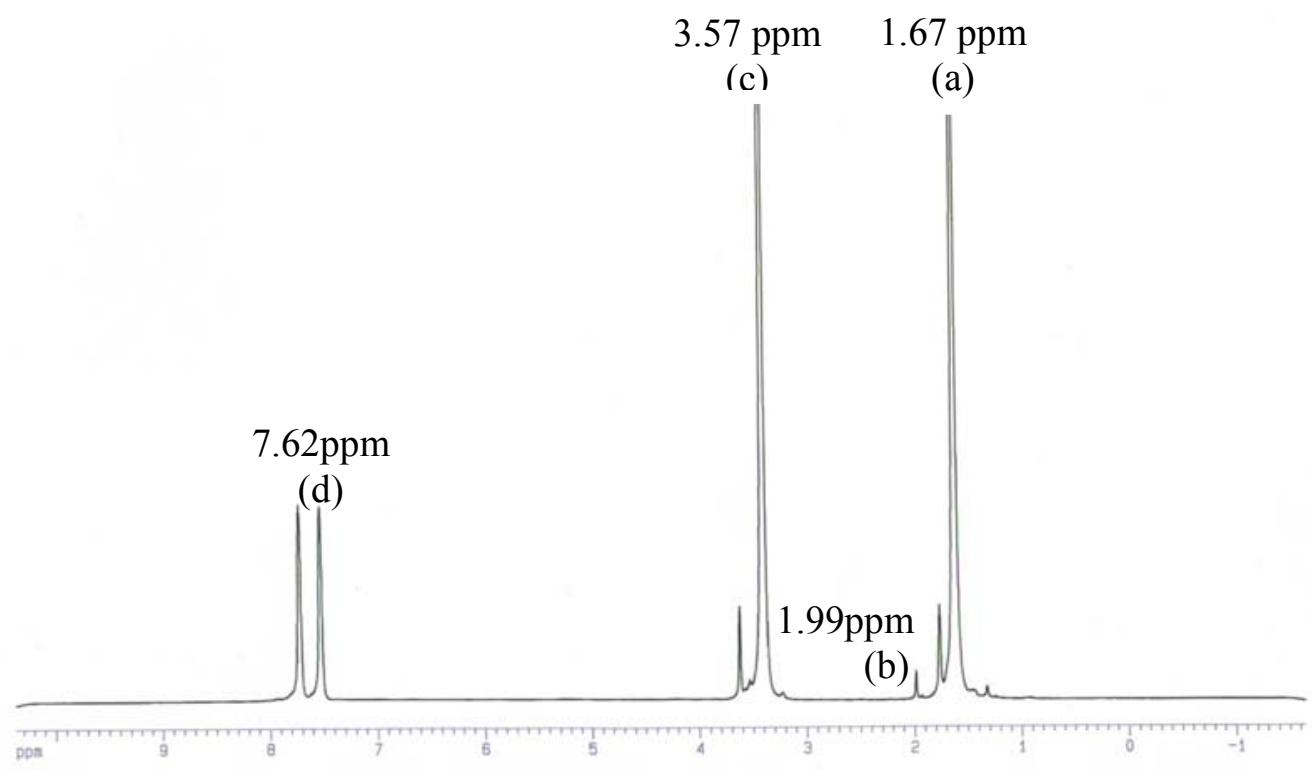

According to the work published by Hamilton and Semlyen [27] and Vivas and Contreras [28] the $300 \mathrm{MHz}{ }^{1} \mathrm{H}-\mathrm{NMR}$ spectra (in deuterated THF, Figure 1) showed four sets of peaks, corresponding to the methyl groups of the main chain at $1.99 \mathrm{ppm}$, the $\beta$ methylene groups at $1.67 \mathrm{ppm}$, the $\alpha$ methylene groups at $3.57 \mathrm{ppm}$, and the ethylene groups at $7.62 \mathrm{ppm}$, respectively.

\section{Mechanism of the reaction}

Polycondensations proceed by successive reactions between the functional groups of the reagents. According to the foregoing discussion and the results of product analysis, we suggest the mechanism shown below for the polymerization reaction induced by "H-Maghnite $0.25 \mathrm{M}$ ". In this mechanism we assume that the protons carried by the montmorillonite sheets of "H-Maghnite $0.25 \mathrm{M}$ " induce the polymerization, and these montmorillonite sheets then act as counter-anions. The first stage is the protonation of the acetic anhydride (Figure 2). 
Figure 2

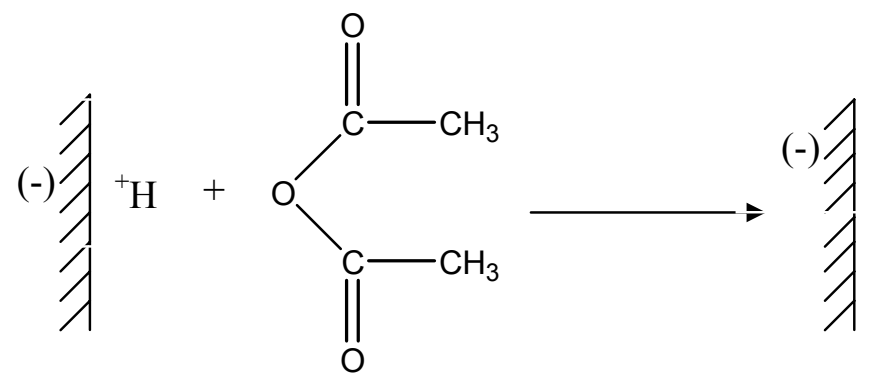<smiles>CC(=O)O</smiles>

Then the protonated acetic anhydride undergoes nucleophilic attack by a THF molecule (Figure 3).

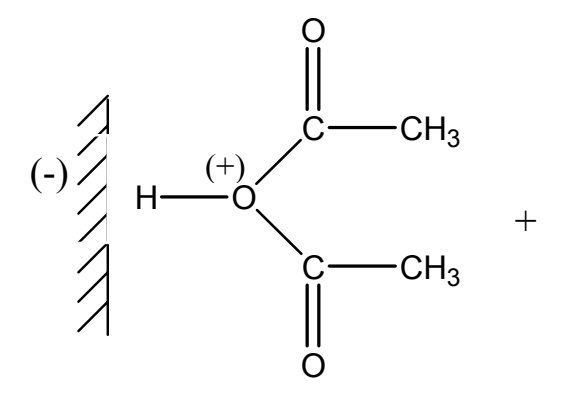

Figure 3<smiles>C1CCOC1</smiles><smiles>CC(=O)O[Ge]1CCCC1</smiles><smiles>CC(=O)O</smiles>

Oxonium ion formation takes place in the vicinity of the counter-anion carried by montmorillonite sheets. Next there is a nucleophilic attack of the maleic anhydride oxygen on the carbon located alpha to the oxygen carrying the positive charge, causing the chains to grow (Figure 4).

\section{Figure 4}
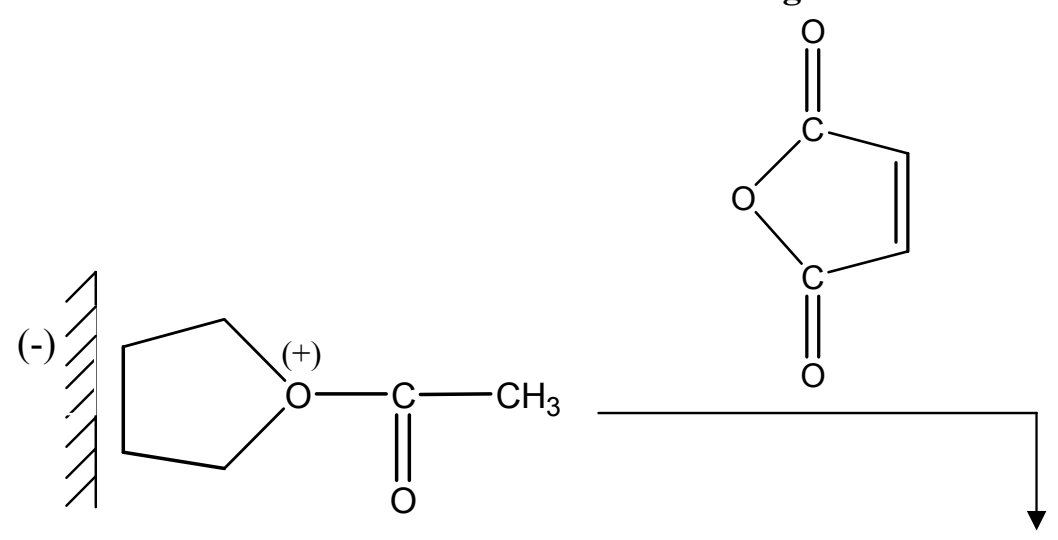<smiles>C[Te]C(=O)C=CC(=O)OCCOC(C)=O</smiles> 
The next stage is a nucleophilic attack of the oxygen of the THF on the carbocation of the chains in growth (Figure 5).

Figure 5<smiles>CC(=O)OCCOC(=O)C=CC(=O)C(C)(C)C(=O)C(C)(C)C</smiles><smiles>[3H]CCC</smiles>

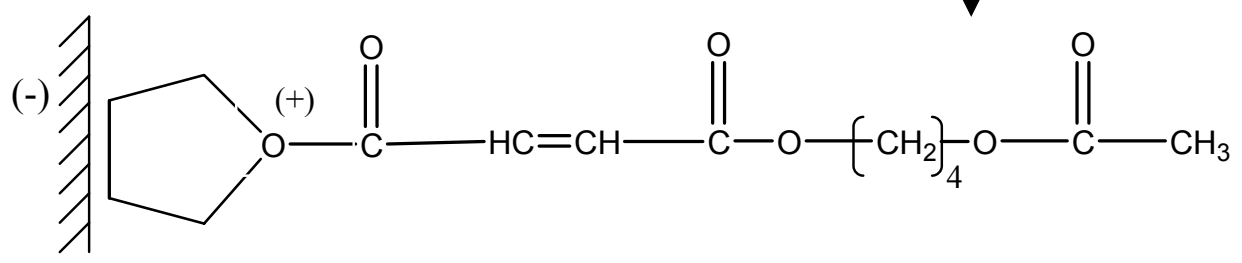

Then we have successive additions of the maleic anhydride followed by THF (Figure 6).

\section{Figure 6}

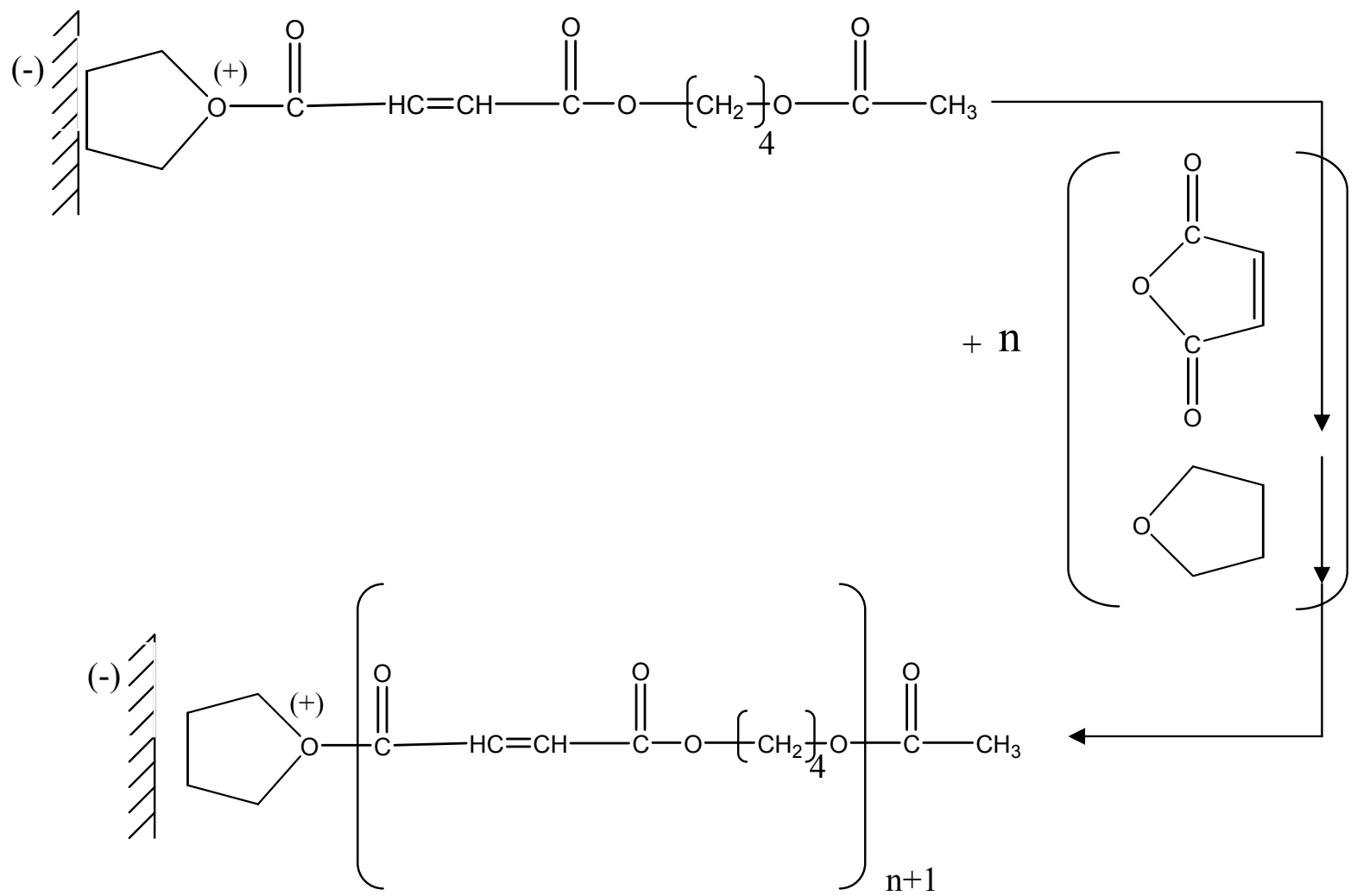


The presence of the acetate groups at the two ends of the chain was clearly identified by ${ }^{1} \mathrm{H}-\mathrm{NMR}$, therefore the last stage must be a nucleophilic attack on the carbon located alpha to the positive charge bearing oxygen of the chains in growth by the oxygen of the acetic acid formed in the first stage from the protonation of acetic anhydride and release of the chain from the montmorillonite, which is now protonated again (Figure 7).

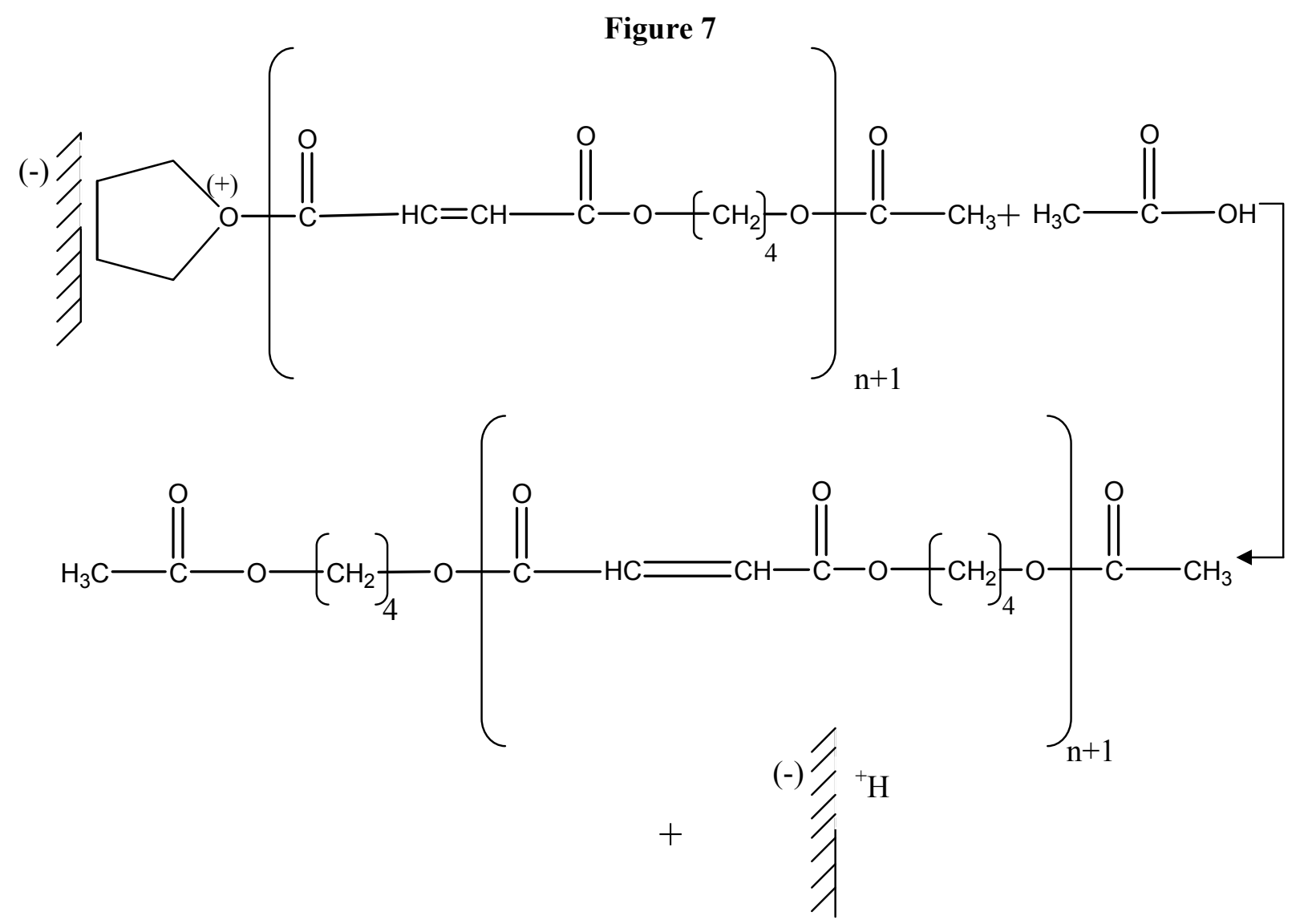

\section{Conclusions}

In conclusion, we have found that acid-exchanged maghnite is effective as an acidic catalyst for the preparation of poly(oxybutylene oxy maleoyl) by using tetrahydrofuran as a source of the oxybutylene part in the polymer in place of butanediol, which is one of the biggest problems with this reaction. The polymerization proceeds smoothly, and a simple filtration is sufficient to recover the catalyst.

\section{Experimental}

\section{General}

Tetrahydrofuran (99\%), maleic anhydride (99\%), acetic anhydride (99\%) and ethanol (99\%) were used as received. Molecular weights were determined by a Waters high pressure GPC instrument (Model 6000A Pump) equipped with a series of Ultra-Styragel columns (100, 500, 103, 104, $105 \AA$ ), a 2401 Differential Refractometer and a Model 440 UV Absorbance Detector. The flow rate of the 
tetrahydrofuran (THF) eluent was $1 \mathrm{~mL} / \mathrm{min}$. The calibration curve was constructed with wellfractionated poly(oxybutyleneoxymaleoyl) standards. ${ }^{1} \mathrm{H}-\mathrm{NMR}$ spectra were recorded on an AM 300 FT Bruker instrument using deuterated THF as solvent, and tetramethylsilane (TMS) as internal standard.

\section{Catalyst Preparation}

"Maghnite- $\mathrm{H}^{+}$xM" were prepared by a method similar to that described by Belbachir et al. [25]. Crude maghnite ( $20 \mathrm{~g}$ ) was crushed for 20 min using a Prolabo ceramic ball grinder. It was then dried by baking at $105{ }^{\circ} \mathrm{C}$ for $2 \mathrm{~h}$. The maghnite was then weighed and placed in an Erlenmeyer flask together with distilled water $(500 \mathrm{~mL})$ and magnetically stirred maghnite/water mixture was combined with sulfuric acid until saturation was achieved. After 2 days at room temperature the mineral was washed with water until it became sulfate free and then dried at $150{ }^{\circ} \mathrm{C}$. Sulfuric acid solutions of $0.05 \mathrm{M}, 0.10 \mathrm{M}, 0.15 \mathrm{M}, 0.20 \mathrm{M}, 0.25 \mathrm{M}, 0.30 \mathrm{M}$ and $0.35 \mathrm{M}$ concentration were used to prepare "Maghnite- $\mathrm{H}^{+}$0.05M", “Maghnite- $\mathrm{H}^{+} \quad 0.10 \mathrm{M} "$, "Maghnite- $\mathrm{H}^{+} \quad 0.15 \mathrm{M} "$, "Maghnite- $\mathrm{H}^{+} \quad 0.20 \mathrm{M}$ ", “MaghniteH $\mathrm{H}^{+}$0.25M", "Maghnite- $\mathrm{H}^{+}$0.30M" and "Maghnite- $\mathrm{H}^{+} 0.35 \mathrm{M}$ ”, respectively.

\section{Polymerization Procedure and Polymer Characterization}

Polymerizations were carried out in stirred flasks at $40{ }^{\circ} \mathrm{C}$. The catalyst was dried in a muffle furnace at $120^{\circ} \mathrm{C}$ overnight and then transferred to a vacuum desiccator containing $\mathrm{P}_{2} \mathrm{O}_{5}$. After cooling to room temperature under vacuum, the mineral was added to the tetrahydrofuran $(10.75 \mathrm{~mol} / \mathrm{L})$, maleic anhydride $(8.43 \mathrm{~mol} / \mathrm{L})$ and acetic anhydride $(1.28 \mathrm{~mol} / \mathrm{L})$ mixtures previously kept in the stirred flask at $40^{\circ} \mathrm{C}$. After the required time an aliquot of the reaction mixture was then removed in such a manner as to exclude any clay mineral and slowly added to ethanol with stirring. The precipitated polymer was filtered off, dried under vacuum and weighed. The polymers were redissolved in THF and precipitated in ethanol for characterization and molecular weight measurements.

\section{References}

1. Belbachir, M. U.S. Patent. 09/535,984, 2001.

2. Aldridge, L. P.; McLaughlin, J. R.; Pope, C. G. J. Catal. 1973, 30, 409.

3. Forni, L. Catal. Rev.1973, 8, 65.

4. Fripiat, J. J.; Gastuche, M. C.; Richard, R. B. J. Phys. Chem. 1962, 66, 806.

5. Theng, B. K. G. Dev. Sedimentol. 1982, 35, 197.

6. Kowalska, M.; Cock, D.L. Chemosphere 1998, 36, 547.

7. Evangetou, V.P.; Marsi, M.; Vandiviere, M.M. Plant Sol. 1999, 213, 63.

8. Kwon, O.Y.; Park, K.W.; Jeong, S.Y. Bull. Korean Chem. Soc. 2001, 22, 678.

9. Ballantine, J. A.; Davies, M.; O’Neil, R. M.; Patel, I.; Purnell, J. H.; Williams, K.J.; Thomas, J. M. J. Mol. Catal. 1984, 26, 57.

10. Lee, D. G.; Nomeldin, N. Tetrahedron Lett. 1981, 22, 4889.

11. Chiang, C. S.; McKillop, A.; Taylor, E. C.; White, J. F. J. Am. Chem. Soc. 1976, 98, 6750.

12. Coenélis, A.; Laszlo, P. Synthesis, 1985, 909. 
13. Ballantine, J. A.; Puenell, J. H.; Thomas, J. M. J. Mol. Catal. 1984, 26, 157.

14. Hojabri, F. J. Appl. Chem. Biotechnol. 1971, 21, 87.

15. Yahyaoui. A.; Belbachir, M.; Hachemaoui, A. Int. J. Mol. Sci. 2003, 4, 572.

16. Thomas, C.L.; Hickey, J.; Stecker, G. Ind. Eng. Chem. 1950, 42, 866.

17. Kaplan, H.; U.S. Patent. 3,287,422, 1966.

18. Hojabri, F.; J. Appl. Chem. Biotechnol. 1971, 21, 87.

19. Ballantine, J.A.; Davies, M.; Purnell, H. J. C. S. Chem. Comm. 1981, 427.

20. Odian, G. La Polymerisation: Principes et Applications; Ed. Technica: New York, 1994; pp. $222-$ 226.

21. Breen , C.;Madejovà,J.; Komadel, P. J. Mater. Chem. 1995, 5, 496.

22. Farmer, V.C. In Infrared Spectra of Minerals, Farmer, V.C., Ed.; Mineralogical Society: London, 1974; p. 331.

23. Moeke, H.H.W. In Infrared Spectra of Minerals, Farmer, V.C., Ed.; Mineralogical Society: London, 1974; p. 365.

24. Madejovà, J.; Bednànikovà, E.; Komadel, P.; Cicel, B. In Proc. 11th Conf. Chem. Miner. Petrol. Ceske Budéjovica 1990; Konta, J., Ed.; Charles University: Prague, 1993; p. 267.

25. Belbachir, M.; Bensaoula, A. US Patent 6,274,527 B, 2001.

26. Ferrahi, M.I; Belbachir, M. Int. J. Mol. Sci. 2003, 4, 312.

27. Hamilton, S.C.; Semlyen, J.A. Polymer 1997, 38, 1685.

28. Vivas, M.; Contreras, J. Eur. Polym. J. 2003, 39, 43.

Sample availability: Contact the corresponding author.

(C) 2004 by MDPI (http://www.mdpi.org). Reproduction is permitted for noncommercial purposes. 